\title{
Safety and efficacy of retrograde cerebral perfusion as an adjunct for cerebral protection during surgery on the aortic arch
}

\author{
Leonard N. Girardi, MD, Nikolay Shavladze, MD, Art Sedrakyan, PhD, and \\ Siyamek Neragi-Miandoab, MD
}

\begin{abstract}
Objective: The best adjunct for cerebral protection during aortic arch reconstruction remains controversial. Retrograde cerebral perfusion (RCP) as an adjunct to profound hypothermic circulatory arrest (PHCA) extends the tolerable period of brain ischemia by flushing emboli and air from the cerebral circulation while maintaining hypothermia. We examined our experience with RCP to determine its efficacy in patients undergoing complex arch reconstruction.

Methods: We retrospectively evaluated 879 patients undergoing arch reconstruction using RCP from July 1997 to March 2013. Perioperative risk factors were analyzed as predictors of neurologic injury and mortality. Survival for the type of arch reconstruction and for the interval of PHCA was calculated.

Results: Of the 879 patients, 671 underwent hemiarch and 208 total arch replacement. The mean age was $65 \pm$ 13.3 years, and $61.6 \%$ were men. The total arch patients had longer mean periods of PHCA (39 vs 21 minutes, $P<.001)$ and RCP (37 vs 19 minutes, $P<.001)$. However, the incidence of transient neurologic dysfunction $(3.0 \%$ vs $2.4 \%, P<.813)$ and permanent neurologic dysfunction $(1.3 \%$ vs $1.9 \%, P<.519)$ was similar for both techniques. Mortality was greater in the hemiarch group $(4.8 \%$ vs $0.5 \%, P<.003)$. Patients requiring $>40$ minutes of PHCA had outcomes similar to those requiring less. The 1-, 5-, and 10-year survival was similar, regardless of the procedure performed or interval of PHCA.
\end{abstract}

Conclusions: $\mathrm{RCP}$ is a safe and effective adjunct for cerebral protection during arch surgery. Patients requiring more extensive arch reconstruction are not at greater risk of permanent neurologic dysfunction or perioperative mortality. (J Thorac Cardiovasc Surg 2014;148:2927-35)

Deep hypothermic circulatory arrest (DHCA) has been a mainstay of cerebral protection for aortic arch reconstruction for nearly 4 decades. Since the introduction of this technique into the adult population by Griepp and colleagues, ${ }^{1}$ profound hypothermia has been the most commonly used method for prevention of permanent and temporary neurologic dysfunction in patients requiring surgery for arch pathologic entities. As the primary brain protection strategy, however, DHCA has its limitations. Svensson and colleagues $^{2}$ demonstrated that the risk of permanent cerebrovascular accident (CVA) increased after 45 minutes of hypothermic arrest and the risk of death increased dramatically when DHCA was needed for periods $>60$ minutes. $^{3}$ A more recent examination of straight deep hypothermia confirmed the limitations of this technique during longer periods of circulatory arrest and also revealed a substantial

From the Department of Cardiothoracic Surgery, Weill Cornell Medical College, New York, NY.

Disclosures: Authors have nothing to disclose with regard to commercial support.

Read at the 94th Annual Meeting of The American Association for Thoracic Surgery, Toronto, Ontario, Canada, April 26-30, 2014.

Received for publication April 22, 2014; revisions received June 27, 2014; accepted for publication July 1, 2014; available ahead of print Aug 28, 2014.

Address for reprints: Leonard N. Girardi, MD, Department of Cardiothoracic Surgery, Weill Cornell Medical College, 525 E. 68th St, Suite M404, New York, NY 10065 (E-mail: lngirard@med.cornell.edu).

$0022-5223 / \$ 36.00$

Copyright (c) 2014 by The American Association for Thoracic Surgery

http://dx.doi.org/10.1016/j.jtcvs.2014.07.024 percentage of these permanent neurologic injuries were secondary to hypoperfusion rather than embolic events. ${ }^{4}$

To reduce the incidence of CVA, transient neurologic dysfunction (TND), and death, adjuncts such as barbiturates, steroids, and topical cooling have been used in conjunction with profound hypothermia to possibly extend the tolerable period of circulatory arrest. ${ }^{5,6}$ The 2 most commonly used adjuncts, however, have been retrograde cerebral perfusion (RCP) and antegrade cerebral perfusion (ACP). RCP is attractive in its simplicity. It flushes atherosclerotic debris and air out of the cerebral circulation, maintains brain hypothermia while the circulation is arrested, and avoids great vessel manipulation with its potential for atherosclerotic emboli. ${ }^{7}$ Its detractors have cited animal studies showing negligible brain capillary blood flow during RCP in both a primate and a porcine model. ${ }^{8,9} \mathrm{ACP}$ clearly provides nutritive brain blood flow and in some studies has proved beneficial when the period of circulatory arrest exceeds 45 minutes. $^{10,11}$ The continuation of brain perfusion during ACP has also encouraged investigators to use lesser degrees of hypothermia in the hopes of shortening the length of surgery, reducing the systemic inflammatory response, and minimizing the incidence of clinically significant bleeding. ${ }^{12,13}$ Currently, ACP is the most commonly used adjunct for brain protection during arch reconstruction. However, single-center randomized trials and large meta-analyses have failed to show an advantage of ACP versus RCP. ${ }^{11,14}$ 


\section{Abbreviations and Acronyms \\ $\mathrm{ACP}=$ antegrade cerebral perfusion \\ $\mathrm{CPB}=$ cardiopulmonary bypass \\ CVA = cerebrovascular accident \\ $\mathrm{DHCA}=$ deep hypothermic circulatory arrest \\ PND = permanent neurologic deficit \\ $\mathrm{RCP}=$ retrograde cerebral perfusion \\ $\mathrm{TND}=$ transient neurologic dysfunction}

During the past 15 years, we have continued to use RCP as an adjunct to PHCA during aortic arch reconstruction. We wished to examine whether patients undergoing complex total arch reconstruction were at greater risk of neurologic injury and mortality compared with patients who were undergoing hemiarch reconstruction and requiring shorter periods of circulatory arrest. We also sought to determine whether previously defined time restrictions on tolerable circulatory arrest were still valid when RCP was used as an adjunct.

\section{METHODS \\ Patients}

A retrospective review of the cardiothoracic surgery department's aortic surgery database was conducted to identify patients undergoing surgery requiring PHCA and RCP from July 1997 to March 2013. The institutional review board approved the study and waived the need for individual patient consent.

All patients undergoing aortic arch reconstruction were examined, including those undergoing surgery for acute aortic pathologic features. Of the 921 patients included in the database, 25 required the assistance of PHCA for tumor removal (eg, renal cell carcinoma with caval extension, T4 mediastinal tumors). An additional 17 patients required the assistance of PHCA for either congenital conditions or cerebral aneurysm clipping. Both of these subsets of patients were excluded, leaving 879 patients available for statistical analysis. The patients were followed up until the point of their last computed tomography scan or death.

\section{Anesthesia and Surgical Procedures}

General anesthesia was induced with intravenous midazolam hydrochloride and sodium pentothal or propofol, followed by fentanyl citrate boluses. Paralysis was maintained using vecuronium bromide. All patients received invasive hemodynamic monitoring with an arterial line and right heart catheter. For patients with arch pathology emanating from the ascending aorta, the procedures were performed through a median sternotomy $(\mathrm{n}=839)$. For patients with arch pathology extending varying lengths into the descending aorta or thoracoabdominal aorta, surgery was performed through a fifth interspace thoracotomy and extended into the abdomen as necessary $(\mathrm{n}=40)$. These patients with a concomitant descending aorta or thoracoabdominal aorta also received single lung ventilation and spinal drainage catheters.

Before the initiation of cardiopulmonary bypass (CPB), the patients were given $400 \mathrm{IU} / \mathrm{kg}$ of heparin. An activated clotting time $>480$ seconds signified adequate anticoagulation. The patients were given a loading dose of $10 \mathrm{~g}$ of aminocaproic acid (Amicar) and a $1 \mathrm{~g} / \mathrm{h}$ infusion throughout the case; $10 \mathrm{~g}$ was also added to the $\mathrm{CPB}$ circuit. Most patients received central aortic cannulation $(n=626)$, and 251 received femoral or axillary $(n=2)$ cannulation. The flows on CPB were maintained at $2.4 \mathrm{~L} / \mathrm{min} / \mathrm{m}^{2}$ at normothermia and $1.8 \mathrm{~L} / \mathrm{min} / \mathrm{m}^{2}$ during periods of cooling. The mean arterial pressure was maintained at 70 to $80 \mathrm{~mm} \mathrm{Hg}$ at all times, regardless of the flow or temperature. Near infrared spectroscopy was used to confirm symmetric cerebral cooling and warming (Somanetics, Corp, Troy, Mich). The patient's head was packed in ice once cooling began. The patients were cooled to $18^{\circ} \mathrm{C}$ for a minimum of 30 minutes (mean, $33.56 \pm$ 4.9). Three minutes before arresting the circulation, $500 \mathrm{mg}$ of methohexital (Brevital) was administered. The patient was then placed into the Trendelenburg position and the circulation arrested.

During PHCA, blood was given through the superior vena cava cannula at $150 \mathrm{~mL} / \mathrm{min}$ and $300 \mathrm{~mL} / \mathrm{min}$ at $14^{\circ} \mathrm{C}$, keeping the central venous pressure $<30 \mathrm{~mm} \mathrm{Hg}$. Arch reconstruction was performed with a Hemashield Dacron graft (Macquet Corp, Oakland, NJ), using 1 of 4 basic techniques: hemiarch replacement, total arch replacement with great vessel reimplantation as an island, total arch with an elephant trunk, or total arch with great vessel debranching. All inaccessible suture lines were reinforced circumferentially with interrupted horizontal mattress Teflon felt pledget reinforced polypropylene sutures. After arch reconstruction, CPB was resumed through a prefabricated branched graft off of the main arch graft. RCP was maintained until full flow on CPB has been re-established. Once the anastomotic sites were thought to be hemostatic, systemic warming ensued (mean warming time, 71.7 minutes), keeping a gradient of $10^{\circ} \mathrm{C}$ between the blood and the patient's core temperature. CPB was discontinued at $35^{\circ} \mathrm{C}$. After protamine administration, the blood products were given as necessary. The patient was closed and transferred to the intensive care unit.

Demographic data and perioperative complications were collected for all patients. Perioperative mortality was defined as death occurring within 30 days of surgery or at any time during the initial hospitalization. Permanent neurologic deficits (PNDs) were defined as stroke, coma, or any new focal neurologic deficit that persisted $>48$ hours, accompanied by computed tomography or magnetic resonance imaging findings confirming a new brain injury. TND was defined as the presence of delirium, agitation, confusion, seizure, or a focal motor deficit lasting $\leq 72$ hours without evidence of new cerebral injury on either a computed tomography scan or magnetic resonance imaging study.

Postoperative renal insufficiency was defined as doubling of the serum creatinine or the need for hemodialysis. Pulmonary complications were defined as ventilator support $>48$ hours, reintubation, adult respiratory distress syndrome, pneumonia, or the need for tracheostomy.

\section{STATISTICAL ANALYSIS AND DATA MANAGEMENT}

All the data collected from July 1997 to March 2013 were stored using Microsoft Access (2010) software (Microsoft, Redmond, Wash). A total of 879 patients were included in the analysis.

The chi-square test was used to compare the categorical variables. Univariate associations were tested by Pearson correlation coefficients for continuous variables. Factors with a $P$ value $<.2$ in linear univariate analysis were included in the multivariate analysis. Logistic and Cox regression analysis were used as methods of multivariate analysis to establish the predictive capacity of different pre- and intraoperative factors on postoperative complications and mortality.

The Kaplan-Meier estimator with and without an adjacent log-rank test was used to assess the long-term survival and to compare the survival distributions.

All tests were 2-tailed. The data were analyzed using IBM SPSS, version 22.0 (IBM, Armonk, NY). 
TABLE 1. Patient demographics

\begin{tabular}{|c|c|c|c|}
\hline Demographic data & Hemiarch $(n=671)$ & Total $\operatorname{arch}(n=208)$ & $P$ value \\
\hline Age $>65 y$ & $406(60.5)$ & $136(65.4)$ & .221 \\
\hline Male sex & $421(62.7)$ & $118(56.7)$ & .122 \\
\hline Mean aortic aneurysm diameter $(\mathrm{cm})$ & $5.86 \pm 1.36$ & $6.6 \pm 1.46$ & .0001 \\
\hline Previous CVA & $101(15.1)$ & $37(17.8)$ & .383 \\
\hline Previous MI & $125(18.6)$ & $23(11.1)$ & .011 \\
\hline HTN & $645(96.1)$ & $199(95.7)$ & .839 \\
\hline COPD & $145(21.6)$ & 45 (21.6) & .99 \\
\hline Preoperative dialysis & $15(2.2)$ & $4(1.9)$ & .79 \\
\hline Connective tissue disease & $17(2.5)$ & $13(6.3)$ & .015 \\
\hline Previous OHS & $148(22.1)$ & $58(27.9)$ & .092 \\
\hline Status of procedure (urgent or emergency) & $346(51.6)$ & $74(35.6)$ & .0001 \\
\hline Acute type A dissection & $198(25.0)$ & $28(13.5)$ & .001 \\
\hline Aortic rupture & $46(6.9)$ & $16(7.7)$ & .645 \\
\hline
\end{tabular}

Data presented as n (\%) or mean \pm standard deviation. $C V A$, Cerebrovascular accident; $M I$, myocardial infarction; $H T N$, hypertension; $C O P D$, chronic obstructive pulmonary disease; $O H S$, open heart surgery.

\section{RESULTS}

The patients were separated into 2 groups for analysis according to the complexity of their surgery. Total arch reconstruction $(n=208)$ consisted of reimplantation of the great vessels as an island $(n=134)$, total arch or island with an elephant trunk $(\mathrm{n}=72)$, and total arch replacement with great vessel debranching $(n=2)$. All other arch procedures consisted of hemiarch reconstruction $(n=671)$.

The patient demographics are listed in Table 1. The mean age of the 879 patients was $65 \pm 13.3$ years. Most were men (539 of $879,61 \%)$. Of the 879 patients, $51(5.8 \%$ ) had presented with aortic rupture. The total arch group had a greater percentage of patients with known connective tissue disorders ( 13 of $208,6.3 \%$, vs 17 of $671,2.5 \% ; P<.015$ ), and the hemiarch groups had more patients with previous myocardial infarction (125 of 671, 18.6\%, vs 23 of 208 , $11 \% ; P<.011)$. A significantly greater percentage of hemiarch operations were performed under urgent or emergency conditions (346 of $671,52 \%$, vs 74 of $208,36 \%$;
$P<.0001)$. The hemiarch group also had nearly twice the percentage of patients with acute type A dissection (198 of $671,30 \%$, vs 28 of $208,14 \% ; P<.001$ ). Five patients ( 5 of $671,0.7 \%$ ) in the hemiarch group presented with acute type A dissection and rupture who were taken to the operating room with ongoing cardiopulmonary resuscitation. All other preoperative risk factors were similar between the 2 groups.

The intraoperative data are listed in Table 2. The patients undergoing total arch replacement had significantly longer mean periods of PHCA ( $39.92 \pm 12.14$ vs $21.33 \pm 6.30 \mathrm{mi}-$ nutes; $P<.0001)$ and RCP $(36.94 \pm 10.57$ vs $19.88 \pm 6.35$ minutes $P<.0001)$ than those undergoing hemiarch replacement. Those undergoing total arch replacement also had longer periods of cardiac ischemia and $\mathrm{CPB}$ time. The increase in these 2 parameters occurred despite the greater number of complex aortic root reconstructions and aortic valve replacements in the hemiarch group. No significant difference was found in the percentage of

TABLE 2. Intraoperative data

\begin{tabular}{|c|c|c|c|}
\hline Variable & $\operatorname{Hemiarch}(n=671)$ & Total $\operatorname{arch}(n=208)$ & $P$ value \\
\hline Cooling time (min) & $34.55 \pm 5.00$ & $34.64 \pm 4.38$ & .811 \\
\hline Warming time (min) & $72.00 \pm 15.92$ & $69.51 \pm 14.18$ & .044 \\
\hline Circulatory arrest time (min) & $21.33 \pm 6.30$ & $39.92 \pm 12.14$ & .0001 \\
\hline $\mathrm{RCP}$ time (min) & $19.88 \pm 6.35$ & $36.94 \pm 10.57$ & .0001 \\
\hline Pump time (min) & $145.97 \pm 33.33$ & $158.39 \pm 34.62$ & .0001 \\
\hline Total cardiac ischemic time (min) & $90.76 \pm 35.87$ & $102.70 \pm 34.03$ & .0001 \\
\hline \multicolumn{4}{|l|}{ Concomitant procedures } \\
\hline Ascending tube graft & $459(64.8)$ & $166(79.8)$ & .02 \\
\hline CVG & $153(22.8)$ & $33(15.9)$ & .033 \\
\hline Aortic valve replacement & $137(20.4)$ & $32(15.4)$ & .131 \\
\hline CABG & $138(20.6)$ & $39(18.8)$ & 621 \\
\hline Aortic valve repair & $182(27.1)$ & $44(21.1)$ & .102 \\
\hline No blood products received during surgery & $334(49.8)$ & $105(50.5)$ & .874 \\
\hline
\end{tabular}

Data presented as mean \pm standard deviation ( $95 \%$ confidence interval) or n (\%). RCP, Retrograde cerebral perfusion; $C V G$, composite valve graft; $C A B G$, coronary artery bypass grafting. 
TABLE 3. Perioperative morbidity and mortality

\begin{tabular}{lccc}
\hline \multicolumn{1}{c}{ Variable } & $\begin{array}{c}\text { Hemiarch } \\
(\mathbf{n = 6 7 1 )}\end{array}$ & $\begin{array}{c}\text { Total arch } \\
(\mathbf{n}=\mathbf{2 0 8})\end{array}$ & $\boldsymbol{P}$ value \\
\hline TND & $20(3.0)$ & $5(2.4)$ & .813 \\
PND & $9(1.34)$ & $4(1.9)$ & .519 \\
Postoperative respiratory complications & & & .758 \\
$\quad$ Prolonged intubation & $22(3.3)$ & $6(2.9)$ & .99 \\
$\quad$ Pneumonia & $6(0.9)$ & $1(0.48)$ & .99 \\
$\quad$ Reintubation & $4(0.6)$ & $3(1.44)$ & .366 \\
$\quad$ Tracheostomy & $24(3.6)$ & $8(3.8)$ & .834 \\
Postoperative dialysis & $16(2.4)$ & $3(1.44)$ & .328 \\
SWI & $6(2.9)$ & $2(0.96)$ & .95 \\
Re-exploration for postoperative & $29(4.3)$ & $11(5.3)$ & .569 \\
$\quad$ bleeding & & & \\
Perioperative mortality & $32(4.8)$ & $1(0.48)$ & .003 \\
\hline
\end{tabular}

Data presented as n (\%). TND, Transient neurologic deficit; $P N D$, permanent neurologic deficit; SWI, sternal wound infection.

patients in either group receiving blood transfusions in the operating room.

The perioperative morbidity and mortality for all $879 \mathrm{pa}-$ tients are listed in Table 3. The incidence of PND (hemiarch, 9 of $671,1.3 \%$, vs total, 4 of $208,1.9 \% ; P<.519$ ) was similar in both groups despite the longer periods of PHCA in the total arch cohort. Similar results were also seen for TND. The need for a return to the operating room for postoperative hemorrhage was also quite consistent between the 2 groups. The perioperative mortality was significantly greater in the hemiarch group (32 of $671,4.8 \%$, vs 1 of $208,0.5 \% ; P<.00001)$. No difference was seen in the patients undergoing elective repair; however, most of the difference in mortality was seen in those presenting with acute type A dissection.

The morbidity and mortality in patients undergoing total arch replacement with PHCA times $>40$ or $<40$ minutes are compared in Table 4 . Those with times $>40$ minutes did not have a greater incidence of PND ( 2 of 96, $2.1 \%$, vs 2 of 112 , $1.8 \% ; P<.99$ ) or TND (4 of $96,4.2 \%$, vs 1 of $112,0.9 \%$; $P<.18)$ than their counterparts with times $<40$ minutes. Respiratory complications were more common in those undergoing PHCA for $>40$ minutes ( 14 of $96,14.6 \%$, vs 4 of $112,3.6 \% ; P<.026)$. No difference was found in perioperative mortality ( 1 of $96,1.0 \%$, vs 0 of $112,0 \% ; P<.44$ ).

We examined the outcomes for 34 patients undergoing total arch replacement requiring PHCA $>50$ minutes. The mean PHCA time was 59 minutes (range, 51-89). These patients were younger (mean age, 59.6 years), were more likely to be men $(76.5 \%)$, and had larger aneurysms (mean diameter, $6.63 \mathrm{~cm}$ ). A significantly greater percentage had had previous open heart surgery (20 of $34,58.8 \%$ vs 38 of $174,21.8 \% ; P<.001)$. Most of their previous operations (19 of $20,95 \%$ ) had been aortic. Despite a longer PHCA period, no increase occurred in the incidence of PND ( 1 of $34,2.9 \%$ ) or TND ( 1 of $34,2.9 \%$ ). Postoperative respiratory complications were more prominent $(8$ of 34 ,
TABLE 4. Morbidity and mortality for total arch replacement with periods of $\mathrm{PHCA}<40$ or $>40$ minutes

\begin{tabular}{|c|c|c|c|}
\hline \multirow[b]{2}{*}{ Variable } & \multicolumn{2}{|c|}{$\begin{array}{l}\text { Total arch, circulatory } \\
\text { arrest time (min) }\end{array}$} & \multirow[b]{2}{*}{$P$ value } \\
\hline & $<40(n=112)$ & $\geq 40(n=96)$ & \\
\hline PND & $2(1.8)$ & $2(2.1)$ & .99 \\
\hline TND & $1(0.9)$ & $4(4.2)$ & .184 \\
\hline Postoperative dialysis & $2(1.8)$ & $1(1.0)$ & .99 \\
\hline $\begin{array}{l}\text { Postoperative respiratory } \\
\text { complications }\end{array}$ & $4(3.6)$ & $14(14.6)$ & .026 \\
\hline Intubation $>48 \mathrm{~h}$ & 1 & 5 & .097 \\
\hline Pneumonia & 1 & 0 & .99 \\
\hline Reintubation & 0 & 3 & .097 \\
\hline Tracheostomy & 2 & 6 & .147 \\
\hline $\begin{array}{l}\text { Re-exploration for postoperative } \\
\text { bleeding }\end{array}$ & $3(2.7)$ & $8(8.3)$ & .117 \\
\hline Perioperative mortality & 0 & $1(1.0)$ & .442 \\
\hline
\end{tabular}

Data presented as $\mathrm{n}(\%) . P N D$, Permanent neurologic deficit; $T N D$, transient neurologic deficit.

$23.5 \%$, vs 10 of $174,5.7 \% ; P<.007)$. No perioperative deaths occurred.

The risk factors for TND, PND, and mortality were calculated using multivariate analysis of univariate factors with a $P$ value $<.2$. A previous CVA (odds ratio [OR], $3.4 ; P<.006)$ and chronic obstructive pulmonary disease (OR, 2.4; $P<.051$ ) were independent predictors of postoperative neurologic injury, but the PHCA time was not (OR, $1.0 ; P<.620)$. Female sex (OR, 6.6; $P<.007)$, chronic obstructive pulmonary disease (OR, 3.8; $P<.029)$, hemiarch reconstruction (OR, 2.2; $P<.004)$, PHCA time (OR, $1.1 ; P<.035)$, postoperative renal failure (OR, 15.6; $P<.0001$ ), and postoperative PND (OR, 4.6; $P<.019)$ were independent predictors of perioperative mortality.

The median follow-up period for all patients was 60 months and was $92 \%$ complete. The actuarial survival of patients undergoing hemiarch repair versus total arch repair at 1 , 5 , and 10 years was $89 \%, 77 \%$, and $65 \%$ versus $87 \%, 74 \%$, and $58 \%$, respectively (log-rank $P=.38$; Figure $1, A$ ). The actuarial survival for those with a PHCA time $<40$ versus $>40$ minutes at 1,5 , and 10 years was $88 \%, 78 \%$ and $60 \%$ versus $84 \%, 69 \%$ and $56 \%$, respectively (log-rank $P=.28$; Figure $1, B)$. Patients with a PHCA time $>50$ minutes also had actuarial survival similar to that of their counterparts with a PHCA time $<50$ minutes (log-rank $P=.45$ ).

\section{DISCUSSION}

Aortic arch reconstruction remains a formidable surgical undertaking. A myriad of pathologic entities creates complex anatomy that challenges the surgeon to definitively reestablish the circulation to the body and brain in a timely fashion to avoid permanent end organ damage. As the surgical technique, graft technology, and postoperative care have improved, the morbidity and mortality of arch surgery now rarely result from technical shortcomings leading to 

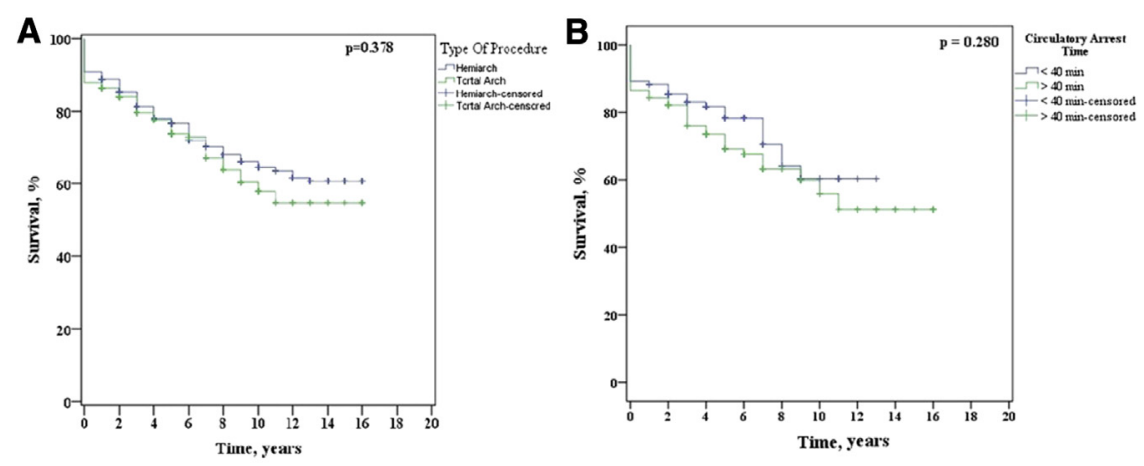

FIGURE 1. A, Kaplan-Meier survival curve for patients with hemiarch and total arch replacement. B, Kaplan-Meier survival curve for patients with total arch replacement with profound hypothermic circulatory arrest time of $<40 \mathrm{vs}>40$ minutes.

catastrophic hemorrhage and massive transfusion. Reexploration for postoperative bleeding occurs in approximately $5 \%$ of cases in many large series, similar to the $4.5 \%$ rate seen in our cohort. ${ }^{4,10}$ When the arch reconstruction is technically sound, profound hypothermia will have little influence on postoperative bleeding. One half of the patients in the present series received no blood products during their operation. Furthermore, those exploring ACP with moderate hypothermia have reported similar or greater rates of postoperative hemorrhage. ${ }^{15-17}$ A contemporary series of patients undergoing arch reconstruction at a mean temperature of approximately $25^{\circ} \mathrm{C}$ reported a re-exploration rate of $15.3 \%$. They still could not demonstrate a relationship between the temperature and bleeding events, even on multivariate analysis. ${ }^{18}$ Despite this fairly high rate of re-exploration, they were also unable to demonstrate a relationship between bleeding and perioperative mortality, even in a propensity-matched cohort. Anastomotic hemorrhage and the significant transfusion associated with this issue is rarely coagulopathic. Most high-volume aortic surgeons show respect for this issue by taking the time to reinforce high-pressure suture lines before resuming CPB. The extra time needed to perform this lifesaving maneuver is irrelevant to either the neurologic outcomes or mortality, as demonstrated by the excellent results witnessed for arch surgery in the current era. Meticulous technique remains the cornerstone of success with arch surgery and is a far more important contributor to the outcome than hypothermia.

Temporary and permanent neurologic dysfunction after arch surgery remains of primary concern and is highly predictive of perioperative mortality and reduced mid- and long-term survival. ${ }^{16}$ In addition, fine neuropsychometric testing can detect neurologic deficits that not only affect mortality but also reduce higher cortical function for $\geq 3$ months after arch reconstruction, even with periods of PHCA of $\leq 25$ minutes. ${ }^{19}$ Patient factors clearly influence the incidence of postoperative PND and TND. Hypertension, cerebrovascular disease, glomerular filtration rate
$<90 \mathrm{~mL} / \mathrm{min}$, atherosclerotic aneurysms, and emergency surgery status have all been associated with worse neurologic outcomes, regardless of the perfusion strategy or the addition of adjuncts for neurologic protection. ${ }^{10,20}$ Intraoperative factors such as the cannulation site, acidbase strategy, and temperature can also contribute to a greater rate of neurologic injury. ${ }^{2} \mathrm{We}$, too, found preoperative comorbid conditions such as previous CVA and chronic obstructive pulmonary disease highly predictive of neurologic injury after arch repair. No doubt exists that patients undergoing such surgery are a relatively high-risk cohort of patients. Compared with their counterparts undergoing coronary artery bypass grafting, the greater incidence of persistent neurocognitive deficits was not surprising. ${ }^{21}$ Many of these factors are not alterable. However, controversy is ongoing about the efficacy of PHCA, RCP, and ACP in preventing stroke, mortality, and neurocognitive deficits. ${ }^{11,14,16,22}$ This controversy is even more pertinent when examining a cohort of patients receiving longer periods of PHCA with an arrest time $>40$ minutes were found to correlate strongly with persistent neurocognitive dysfunction on fine neuropsychometric testing. ${ }^{23}$ Although many of these finer deficits are clinically undetectable, many more patients coming for surgery have complex arch pathologic features that mandate longer CPB times, cardiac ischemia, and PHCA. It is relevant to examine the outcomes of these patients with advanced disease to optimize a neuroprotective strategy. We believe that the data we have presented support the use of RCP in complex arch surgery with a substantial percentage of patients having excellent clinical outcomes.

In our experience, RCP provided equivalent neurologic protection in patients undergoing both simple hemiarch and complex total arch surgery. The risk of PND was $1.9 \%$ in the 208 patients who underwent total arch reconstruction, not significantly different $(P<.52)$ from the $1.3 \%$ rate in the 671 patients who had undergone hemiarch repair. Similarities were also seen in both groups with respect to TND, with neither group experiencing the 
complication $>3 \%$ of the time. Even in the nearly 100 patients requiring $>40$ minutes of PHCA to complete the procedure, permanent neurologic injury occurred at a rate of $2.1 \%$. A small increase was seen in the rate of TND in this $>40$-minute group $(4.2 \%)$, but the difference was not statistically significant. We did not see an increase in the risk of PND or TND in a smaller cohort of patients requiring very extensive periods of circulatory arrest. In those $34 \mathrm{pa}-$ tients, the incidence of both complications was $2.9 \%$, despite a mean PHCA time of 59 minutes (range, 51-87). The mortality in this select group was 0 . These results support those from Estrera and colleagues ${ }^{20}$ who reported a PND rate of $2.8 \%$ in 1107 patients who had undergone arch reconstruction with PHCA and RCP as their strategy of brain protection. Okita and colleagues ${ }^{24}$ reported on their experience in a small group of patients also undergoing arch reconstruction with prolonged periods of circulatory arrest (mean time, 60 minutes). Although their rate of PND $(4 \%)$ was similar to ours and those from other contemporary reports, their $25 \%$ incidence of TND was disappointing. However, nearly one third of their cohort underwent arch reconstruction through a left posterolateral thoracotomy. Delivery of RCP by way of the left chest is less certain, limiting the efficacy of RCP to reliably flush debris and air out of the cerebral circulation. ${ }^{24}$ Although the University of Pennsylvania group did not report the risk of neurologic injury in their cohort of patients with PHCA lasting $>45$ minutes, they, too, reported PND and TND rates of $2.8 \%$ and $3.7 \%$, respectively, in 682 patients who underwent arch reconstruction with the assistance of RCP. $^{10}$

Our results with RCP also compared favorably with those published recently from a large meta-analysis comparing $\mathrm{RCP}$ and ACP. ${ }^{14}$ In that study, $\mathrm{Hu}$ and colleagues, ${ }^{14}$ reported the incidence of CVA in 5060 patients undergoing arch surgery. Patients receiving RCP as their primary adjunct for neurologic protection had a significantly lower risk of postoperative CVA compared with those who received ACP $(4.7 \%$ vs $7.2 \%, P<.01)$. Modifications in the delivery of ACP did not seem to diminish the risk of PND further. Angeloni and colleagues ${ }^{22}$ compared bilateral and unilateral ACP in a meta-analysis of 5100 patients. The risk of PND was $6.1 \%$ with unilateral perfusion and did not decline significantly $(6.5 \%, P=.8)$ when ACP was administered to both hemispheres. Despite continuous perfusion of both carotid circulations, the risk of TND also did not decline $(7.1 \%$ unilateral vs $8.8 \%$ bilateral; $P=.46)$. Although antegrade perfusion of the brain with ACP clearly provides nutritive brain flow, it is difficult to negate the potential for embolic phenomenon created by clamping and manipulating the great vessels. ${ }^{22}$ Although the mechanism of protection with RCP is not completely understood, it is believed that its primary mechanism of neurologic protection is the flushing of atheromatous debris from the cerebral circulation..$^{20}$ Although some concerns have been raised for the potential for cerebral edema with $\mathrm{RCP}^{25}$ power M-mode transcranial Doppler observation of the cerebral circulation during RCP failed to detect differences in the pulsatility index or end-diastolic flow velocities to support this concern. ${ }^{26}$ Whether RCP flushes toxic byproducts of metabolism out of the brain is still debated but could also prove important in explaining the efficacy of this technique.

Regardless of the mechanism of action, RCP minimized the risk of temporary and permanent neurologic injury in our patients undergoing arch reconstruction. These data reinforce the importance of PND and TND as markers of greater perioperative mortality. A postoperative CVA in our experience significantly increased the risk of death (OR, 4.6; $P<.019)$. Misfeld and colleagues ${ }^{16}$ also highlighted the importance of PND to mid-term survival. Those experiencing a neurologic injury during arch surgery had a $<50 \% 3$-year actuarial survival and those without a neurologic event had a 3-year survival rate of $>80 \%$ (log-rank $P<.001$ ).

The present study had limitations that should be considered. The present study was a retrospective, singleinstitution, and single-surgeon experience. The extrapolation of our data to a more heterogeneous population of patients and surgeons might not be applicable. The results could also have been influenced by the much greater percentage of patients undergoing hemiarch repair instead of total arch repair. We performed propensity matching to eliminate the bias presented by such disparate numbers. We identified 55 patients who were appropriately matched. We did not find a significant difference in the outcomes between the 2 groups. Finally, we did not perform advanced neuropsychometric testing on our subjects either before or after surgery. Clearly, such testing is a more sensitive indicator of neurologic injury than clinical observation. We will investigate the potential for this type of study for future patients undergoing arch reconstruction.

\section{CONCLUSIONS}

RCP is a safe and effective adjunct to profound hypothermia for neuroprotection and mortality reduction in patients undergoing aortic arch reconstruction. Additional investigation into its elusive mechanism of action is warranted; however, the avoidance of great vessel manipulation and embolic phenomena is quite advantageous, especially in a population with advanced atherosclerotic disease.

\footnotetext{
References

1. Griepp RB, Stinson EB, Hollingsworth JF, Buehler D. Prosthetic replacement of the aortic arch. J Thorac Cardiovasc Surg. 1975;70:1051-63.

2. Svensson LG, Crawford ES, Hess KR, Coselli JS, Raskin S, Shenaq SA, et al. Deep hypothermia with circulatory arrest: determinants of stroke and early mortality in 656 patients. J Thorac Cardiovasc Surg. 1993;106:19-28; discussion 28-31.

3. Griepp RB. Cerebral protection during aortic arch surgery. J Thorac Cardiovasc Surg. 2001;121:425-7.
} 
4. Gega A, Rizzo JA, Johnson MH, Tranquilli M, Farkas EA, Elefteriades JA. Straight deep hypothermic arrest: experience in 394 patients supports its effectiveness as a sole means of brain preservation. Ann Thorac Surg. 2007;84: 759-66; discussion 766-7.

5. Dewhurst AT, Moore SJ, Liban JB. Pharmacological agents as cerebral protectants during deep hypothermic circulatory arrest in adult thoracic aortic surgery: a survey of current practice. Anaesthesia. 2002;57:1016-21.

6. Shum-Tim D, Tchervenkov CI, Jamal AM, Nimeh T, Luo CY, Chedrawy E, et al. Systemic steroid pretreatment improves cerebral protection after circulatory arrest. Ann Thorac Surg. 2001;72:1465-71; discussion 1471-2.

7. Ueda Y, Okita Y, Aomi S, Koyanagi H, Takamoto S. Retrograde cerebral perfusion for aortic arch surgery: analysis of risk factors. Ann Thorac Surg. 1999;67: 1879-82; discussion 1891-4.

8. Ehrlich MP, Hagl C, McCullough JN, Zhang N, Shiang H, Bodian C, et al. Retrograde cerebral perfusion provides negligible flow through brain capillaries in the pig. J Thorac Cardiovasc Surg. 2001;122:331-8.

9. Boeckxstaens CJ, Flameng WJ. Retrograde cerebral perfusion does not perfuse the brain in nonhuman primates. Ann Thorac Surg. 1995;60:319-27; discussion 327-8.

10. Milewski RK, Pacini D, Moser GW, Moeller P, Cowie D, Szeto WY, et al. Retrograde and antegrade cerebral perfusion: results in short elective arch reconstructive times. Ann Thorac Surg. 2010;89:1448-57.

11. Okita Y, Minatoya K, Tagusari O, Ando M, Nagatsuka K, Kitamura S. Prospective comparative study of brain protection in total aortic arch replacement: deep hypothermic circulatory arrest with retrograde cerebral perfusion or selective antegrade cerebral perfusion. Ann Thorac Surg. 2001;72:72-9.

12. Urbanski PP, Lenos A, Bougioukakis P, Neophytou I, Zacher M, Diegeler A. Mild-to-moderate hypothermia in aortic arch surgery using circulatory arrest: a change of paradigm? Eur J Cardiothorac Surg. 2012;41:185-91.

13. Salazar J, Coleman R, Griffith S, McNeil J, Young H, Calhoon J, et al. Brain preservation with selective cerebral perfusion for operations requiring circulatory arrest: protection at $25^{\circ} \mathrm{C}$ is similar to $18^{\circ} \mathrm{C}$ with shorter operating times. Eur J Cardiothorac Surg. 2009;36:524-31.

14. Hu Z, Wang Z, Ren Z, Wu H, Zhang M, Zhang H, et al. Similar cerebral protective effectiveness of antegrade and retrograde cerebral perfusion combined with deep hypothermia circulatory arrest in aortic arch surgery: a meta-analysis and systematic review of 5060 patients. J Thorac Cardiovasc Surg. 2014;148:544-60.

15. Tsai JY, Pan W, LeMaire SA, Pisklak P, Lee VV, Bracey AW, et al. Moderate hypothermia during aortic arch surgery is associated with reduced risk of early mortality. J Thorac Cardiovasc Surg. 2013;146:662-7.

16. Misfeld M, Leontyev S, Borger MA, Gindensperger O, Lehmann S, Legare JF, et al. What is the best strategy for brain protection in patients undergoing aortic arch surgery? A single center experience with 636 patients. Ann Thorac Surg. 2012;93:1502-9.

17. Sundt TM III, Orszulak TA, Cook DJ, Schaff HV. Improving results of open arch replacement. Ann Thorac Surg. 2008;86:787-96.

18. Kamiya H, Hagl C, Kropivnitskaya I, Böthig D, Kallenbach K, Khaladj N, et al. The safety of moderate hypothermic lower body circulatory arrest with selective cerebral perfusion: a propensity score analysis. J Thorac Cardiovasc Surg. 2007; 133:501-9.

19. Harrington DK, Bonser M, Moss A, Heafield MT, Riddoch MJ, Bonser RS. Neuropsychometric outcome following aortic arch surgery: a prospective randomized trial of retrograde cerebral perfusion. J Thorac Cardiovasc Surg. 2003; 126:638-44.

20. Estrera AL, Miller CC III, Lee TY, Shah P, Safi HJ. Ascending and transverse aortic arch repair: the impact of retrograde cerebral perfusion. Circulation. 2008;118(Suppl):160-6.

21. Newman M, Kirchner J, Phillips-Bute B, Gaver V, Grocott H, Jones RH, et al. Longitudinal assessment of neurocognitive function after coronary-artery bypass surgery. N Engl J Med. 2001;344:395-402.

22. Angeloni E, Benedetto U, Takkenberg JJM, Stigliano I, Roscitano A, Melina G, et al. Unilateral versus bilateral antegrade cerebral perfusion during circulatory arrest in aortic surgery: a meta-analysis of 5100 patients. J Thorac Cardiovasc Surg. 2014;147:60-7.

23. Chau KH, Friedman T, Tranquilli M, Elefteriades JA. Deep hypothermic circulatory arrest effectively preserves neurocognitive function. Ann Thorac Surg. 2013;96:1553-9.

24. Okita Y, Takamoto S, Ando M, Morota T, Matsukawa R, Kawashima Y. Mortality and cerebral outcome in patients who underwent aortic arch operations using deep hypothermic circulatory arrest with retrograde cerebral perfusion: no rela- tion of early death, stroke and delirium to the duration of circulatory arrest. $J$ Thorac Cardiovasc Surg. 1998;115:129-38.

25. Reich DL, Uysal S, Sliwinski M, Ergin MA, Kahn RA, Konstadt SN, et al. Neuropsychologic outcome after deep hypothermic circulatory arrest in adults. $J$ Thorac Cardiovasc Surg. 1999;117:156-63.

26. Estrera AL, Garami Z, Miller CC III, Sheinbaum R, Huynh TT, Porat EE, et al. Determination of cerebral blood flow dynamics during retrograde cerebral perfusion using power M-mode transcranial Doppler. Ann Thorac Surg. 2003;76: 704-10.

\section{Discussion}

Dr Anthony L. Estrera (Houston, Tex). I have nothing to disclose.

Since Dr Griepp's seminal report on the use of PHCA for total arch replacement, many adjuncts have been devised for use in combination for cerebral protection. Ueda with RCP and Bachet and Kazui with ACP were early proponents.

Currently, most large aortic centers have reported the use of $\mathrm{ACP}$ as the primary mode of cerebral perfusion during hypothermic circulatory arrest, suggesting that the use of RCP has for the most part been abandoned.

The findings from the present report by Girardi and colleagues, in which RCP was used as the primary adjunct for cerebral perfusion during ascending and arch replacement, resulting in very enviable outcomes, stroke of $2 \%$, mortality of $4 \%$, including those with type A dissection, suggest that RCP could still play a pertinent role.

Despite my enthusiasm for RCP during circulatory arrest, I must be candid and discerning of this report by Girardi and colleagues. As acknowledged by the authors, the study was a retrospective analysis with its inherent limitations, occurring during a 15 -year period and, thus, potentially biased by the changes that could have occurred over time.

The study design was more observational than comparative, because no true control group was designated. Because it was a single-center and single-surgeon study, the results should not necessarily be generalized. Despite these issues, it was a very large series that provides value in the questions that arise from such a study.

I have a few questions that can be answered consecutively.

First, the atheromatous burden remains a significant risk factor for stroke after cardiovascular surgery. Do you have any information on the degree of aortic atheromatous disease, and can you please comment on your interrogation methods before cannulating the ascending aorta?

Dr Girardi. Yes, and thank you very much, Dr Estrera.

So, before surgery, all our patients underwent transesophageal echocardiography. In those patients who were deemed to have grade 4 or 5 disease, we then tried to use epiaortic scanning. We also used epiaortic echocardiography if we had found palpably significant calcium in the ascending aorta or arch in the area in which we were anticipating cannulation.

Also, in those patients with a very hostile ascending aorta, we will switch to femoral access, which does not adversely affect our stroke risk. Obviously, computed tomography or magnetic resonance imaging will provide us with some idea of what is present in the descending aorta, and we can also see that with transesophageal echocardiography. 
Dr Estrera. Second, can you describe in more detail your temperature management during repair? How was your temperature measured? What determined how long you cool? I noticed it was about 33 minutes as the mean cooling time.

Dr Girardi. We have avoided electroencephalographic monitoring while cooling. It was just a logistical problem for us. We used it early in our experience and found that if we went to electroencephalographic silence, it did not necessarily eliminate our neurologic problems, especially with TND. Not so much permanent deficits, but TND was still a problem if we cooled for $<25$ minutes or so.

We set a minimum of 30 minutes as our mark. We used the bladder temperature as our cooling monitor. If the patient was anuric from end-stage renal disease, we used a tympanic probe. We have not found anything else to be terribly reliable.

Dr Estrera. Third, please elaborate on your neuromonitoring approach. Do the near-infrared spectroscopy (NIRS) findings change what you do? Do you modify your RCP perfusion pressures during circulatory arrest if you do see changes?

Dr Girardi. Yes. We have used NIRS mostly to monitor perfusion when we return to CPB. For the patients with acute type A dissection, we use it when we first start CPB, because certainly cerebral malperfusion can happen when you are using femoral cannulation. We have seen it once or twice, and that has, on an emergency basis, changed our method of perfusion.

We also use it when we return to CPB after circulatory arrest, because we want to ensure that we have been perfusing both hemispheres equally. Also, I think it is very sensitive for showing that.

Regarding the trends with the patient under circulatory arrest, we have seen most of the time that the NIRS is around 60 or 70 . Occasionally, after 40,50 minutes, it might decrease 5 or 10 points, but not more than that.

When you consider the general population of patients undergoing CPB, NIRS monitoring is not particularly sensitive at detecting a real problem until the finding is less than about $30 \%$, which we rarely, if ever, see.

Dr Estrera. Finally, as many would have me believe, is RCP dead?

Dr Girardi. I do not think RCP is dead, and I know a few of us out there are still using it. I understand the concerns for it, but I think, as you can see from Dr Elefteriades' presentation, I think hypothermia is the key element of brain protection. Whether you add on RCP or ACP in addition to cold or just use straight profound hypothermia, I think you achieve pretty good protection, particularly with short periods of circulatory arrest.

Also, I think what we are all looking for is what to do with these really complex patients out in that 50- to 60-minute range. Our data would suggest that RCP is safe in that patient population. Of course, as you noted the limitations of the study, it was retrospective and a single-institution, single-surgeon experience.

However, for the overwhelming majority undergoing arch surgery, I think RCP works pretty well.

Dr Yutaka Okita (Kobe, Japan). Recently, we collected Japanese data for 4 years, 8000 cases of total arch replacement, and 1000 received RCP and 7000, ACP.

Virtually RCP people tend to do arch first techniques. It is very short even in total arch replacements.

We found virtually no difference in stroke, TND, or early mortality. However, we found the RCP patients tended to wake up late and stay in the intensive care unit longer. Also, ACP patients usually woke up on the day of the operation. The RCP patients woke up the next day and they extubated late. Did you consider this wake-up time?

Dr Girardi. We did not study the wake-up time per se; however, our transient neurologic deficit rate included those patients who had temporary defects that did not allow them to wake up immediately. Again, confusion, delirium, items along those lines, are difficult to quantify; however, we included all those into our TND experience.

The experience in 2 large meta-analyses with $>5000$ patients in each study showed very little difference between the results with the ACP or RCP. However, meta-analyses have a number of limitations and the data have not convinced me regarding the safety of ACP, either unilateral or bilateral, compared with RCP.

Dr Joseph S. Coselli (Houston, Tex). Len, I am going to jump in with 1 quick question. Returning even to the experience that you referenced with Dr Crawford, when we used a very similar technique to what you described, we encountered a peculiar phenomenon frequently referred to as "supranuclear hemianopsia," which manifested primarily by a disconjugate gaze. However, in the many hundreds of cases, since we have switched to ACP, although it is a rare complication, we just have not seen it anymore. You have a very, very large series. Any experience with that?

Dr Girardi. Thank you Joe. I am familiar with that problem but we did not see that at all, not 1 time.

Dr John A. Elefteriades (New Haven, Conn). First, congratulations on the fantastic results and a beautiful report.

My short question is, is it possible that the RCP is "just along for the ride"?

Dr Girardi. It is possible. I think, just as your group has so eloquently shown, $\leq 40$ minutes with straight hypothermic arrest, things are pretty safe.

I agree with your group that profound hypothermia is the key. Cold has gotten a really bad reputation as you can see with some of the ACP reports that are now espousing moderate hypothermia. Forgive me, I know Dr Coselli's group recently published on this and showed very good results with moderate hypothermia. However, I have a number of concerns about that technique, not only for brain protection, but also for end organ protection, including the kidneys, spinal cord, and gut.

Also, I realize that a number of centers using it on a regular basis have become pretty comfortable with it. However, I do not think that profound hypothermia carries with it the bleeding risks that concerned surgeons in the past. I think if you really take the time to reinforce your suture lines and achieve surgical hemostasis before returning the patient to $\mathrm{CPB}$, bleeding will not be a great risk.

So, I like cold. We like cold. Also, I think up to about $40 \mathrm{mi}-$ nutes, the use of adjunct therapy might not add a lot.

Dr Eric E. Roselli (Cleveland, Ohio). Len, I echo the congratulations from everyone else. Outstanding acute results.

These patients who have disease encroaching on their arch or involving their arch obviously have an entire aorta that is diseased, and what I am concerned about is that at 10 years, we only saw survival of around $60 \%$.

Can you tell us whether you have any information about the modes of death of these patients, and tell us what you do to follow-up these patients. Do you continue to monitor them long term with imaging of their aortas? 
Dr Girardi. Thank you for the question, Eric. Yes, we do follow-up patients with imaging for as long as they will continue to come for their imaging studies or go to their local place for imaging studies and send them to us.

For those patients for whom we were unable to get adequate follow-up data at our institution, we would call the referring physicians, the family, and the Social Security
Death Index to confirm death. However, we were unable to determine the modes of death exactly for many of these patients.

Regarding the need for reintervention on our arch patients, we had a very low rate of reintervention. It was somewhat $<5 \%$ out to 5 to 7 years. We have not published those data yet, but we are compiling the data. 